\title{
John Spencer Madden
}

\author{
In conversation with Greg Wilkinson
}

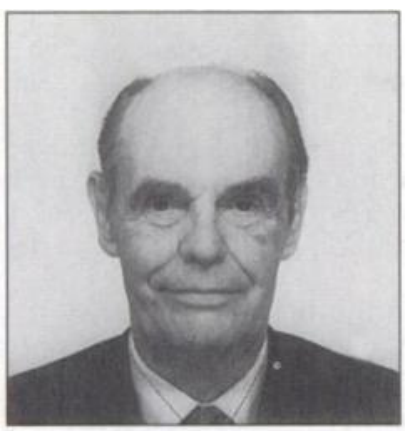

Dr. J. S. Madden
Dr John Spencer Madden was born in 1928 and graduated MB, BCh, BAO in 1951. He was appointed a consultant psychiatrist in the Mersey region in 1960 and was at various times responsible for founding a day hospltal, a regional alcohol and drug dependence service. the second of its kind in the UK and the first outside London, and a rehabilitation service for long-stay psychiatric patients. At the time of interview he was Chairman. Merseyside, Lancashire and Cheshire Council on Alcoholism, and section editor of the journal Current Opinion in Psychiatry (1988-1993). He is deputy editor of the journal Alcohol and Alcoholism

Dr Madden is a Foundation Fellow of the Royal College of Psychiatrists and has been Chairman of the Substance Misuse Section, a member of Council, and a member of the Public Pollcy Committee. He was awarded the Fellowship of the Royal College of Physicians of Edinburgh in 1973. Duties and interests continue to comprise general psychiatry as well as substance use.

Greg Wilkinson interviewed Dr Madden on 23 April 1993.
Did you have a medical background?

My father was a dentist and I followed his life example by entering Dental School at the University of Liverpool when aged 16. During my preclinical years I realised that I much preferred medicine. In those days the bachelor of dental surgery course was the same as the MB course for the first three years, except it was harder for dental students. We had to come in during the holidays and make false teeth. I progressed as far as making my first full set of upper and lower dentures on a non-living model.

Two other dental students and I applied to change over to medicine after the second BDS, which was the same as second MB. Similar applications occurred yearly and were routinely refused. When ours were declined I moved to the clinical school at University College Galway.

What attracted you to medictne?

I realised that a wider range of knowledge and skills was required. I should say that I possessed an early interest in psychiatry. Here I have a modest resemblance to Ken Rawnsley in that, as a schoolboy I also went to a school where we were encouraged to visit the public library and borrow books that had nothing to do with our examinations. I borrowed the Interpretation of Dreams and was quite impressed with Freud's explanation of mental processes. Even at that stage I thought his underlying theory - that it all boiled down to sex - was extraordinarily naive.

Did you maintain this interest at university?

In my first year at university I remember buying Jung's large tome Psychological Types. A friend said, "You'll never finish reading that". He was right.

I had to drop an interest in psychological and psychiatric matters until I learnt some psychiatry in the last year but one at medical school.

We had vivid lectures from Conor McCarthy who was superintendent of a mental hospital at Ballinasloe. Neuroses didn't exist in the course, which was confined to psychosis, with rather old fashioned Kraepalinian nosology. He produced a marvellous and colourful array of patients to display their symptoms. I always remember one patient, introduced correctly as having schizophrenia, who told us that he had seen the devil riding a red bicycle with dropped handle bars. I thought, "I would love to know what is in that man's mind". As it happens when I did enter 
psychiatry I went into a rather different area than schizophrenia but I continued to reflect on that case. It took 30 years for the penny to drop that he had been pulling our legs.

After graduation, I completed house jobs in Liverpool, and national service, and I then entered psychiatry.

Where did you do that?

Liverpool had just started a course for the DPM and I was among the first participants on that course, studying at Liverpool University and then going down to London to sit the examination.

Who were your examiners?

One of them was Sir Paul Mallison. He was a hereditary Knight as well as a psychiatrist. I do remember the clinical examiner in neurology was Dennis Williams, who was a very important person, so I felt quite honoured to come across him. He'd written an important paper on identifying EEG foci in affective auras of epilepsy.

Where were you working at this stage?

Rainhill Hospital, Liverpool, and Winwick Hospital, Warrington. We're talking about the mid and late 1950s. Rainhill Hospital had 2,800 patients. Winwick was slightly smaller, at 2,400; it possessed its own fire engine and railway line.

Rainhill had a particularly strong-minded superintendent, Dr Benedict Finkleman. Apart from able medical leadership he could give clear and shrewd directions on the time to obtain the best price for cows reared on the hospital farm.

Were the hospitals divided into specialist units where patients were segregated in various ways?

Segregated by sex and by degree of alleged violence. Both hospitals had refractory wards dreadful places with locks all over the place and an air of tension as soon as you entered. Because of that I've always tried to resist, subsequently, undue pressures to form closed wards for psychiatric patients and I've endeavoured to stimulate opening wards in psychiatric hospitals.

Would you say that there was any community psychiatry in those days in Liverpool?

This comprised out-patient clinics and mental welfare officers. The latter were excellent people who regrettably were replaced by generic social workers. Mental welfare officers were employed by the medical officers of health, not by the NHS. The combined the wisdom of practical experience with commonsense.

In 1957, after obtaining the DPM, I became a senior registrar and helped a consultant, Dr George Egan, to open the first day hospital in Liverpool.
Did it bear a resemblance to day hospitals today?

In many ways. Perhaps a little more emphasis on individual and group psychotherapy - not group counselling. I couldn't have called myself a fullyfledged psychotherapist; like so many colleagues at that time I was self-taught.

\section{What was this psychotherapy?}

Discussing past and present problems, not to a deep level. One aspect that was quite common then and has completely been discarded involved drug-assisted psychotherapy using ether, intravenous injections of sodium amytal, methylamphetamine, or LSD.

One of my chiefs at Rainhill Hospital, Dr Astley Cooper, wrote a fine lengthy letter in the Lancet describing LSD treatment and some of its illeffects. He was among the first people to describe LSD flash-backs.

LSD is interesting because it shows how the effects of a drug depend in many ways on what the drug-taker, in this case the patient, expects. Patients experienced what the psychiatrists forecasted would happen - a vivid recall of memories from childhood which had been repressed or suppressed. I remember watching a man under LSD who was reliving beatings by his father; he groaned as he experienced again the blows.

\section{Did you think LSD had some benefits?}

We did at the time. We thought it helped patients to take a somewhat calmer and more mature view of their problems and of past unfortunate experiences they had undergone.

Liverpool was one of the first cities in this country to have a day hospital.

It was mostly for patients with neurotic disorders but we did treat people with depression who might need ECT. We didn't really see it as a half-way house. It was an extension of treatment for people with milder psychiatric conditions.

You took your Edinburgh Membership, you were a senior registrar, what next?

Then I was looking around for a consultant post. In those days university departments of psychiatry either didn't exist or were rather small. The one in Liverpool, for example, had a Reader in Psychiatry, Dr Stephen Barton Hall, whose wife was also very well known, Murial Barton Hall; she was one of the first child psychiatrists in the country.

\section{What was Dr Hall's interest?}

Out-patient assessment and treatment. He functioned without a personal allotment of beds. He had written a book on psychiatry, a textbook. 
That came out in 1939 and was slightly out-ofdate by my time. In the department of psychiatry in Liverpool there was the reader, a senior lecturer and a lecturer who was the equivalent of a senior registrar - and that was it. There was no academic opening there or elsewhere.

When a consultant post came up in Chester, in what is now the Countess of Chester Hospital, but was then called Deva Hospltal, you applied for that and obtained it.

At that time, throughout the country, but particularly in Liverpool and Manchester regions, there was quite an expansion of consultant posts. The mental hospital in Chester contained about 2,200 patients. It had just acquired a neighbouring ex-Army hospital called Moston Hospital, which was built of wood but was empty, so we used that to move some of the long-stay patients. They had been living in basements of the original building erected in 1829. The basements were intended presumably for cooking and for storage of coal and other commodities. They were squalid, with minimal natural light.

The patients were transferred around the time I arrived at Moston Hospital. One half of Moston was used for that, and the other to open admission wards. In many ways, despite its wooden structure, Moston was quite light, all on the ground floor, with a rectangular corridor off which the wards radiated. Its design was quite enlightened.

Moston possessed a separate bullding that was used to open a day hospital, of which you were the consultant. A colleague (Dr John Richardson) used another building to open a young persons unit.

Someone said we should have an alcoholic unit. I remarked that it was a sound idea; and they said, "Right, you can run it". I didn't mind, as I quite liked the alcoholics I'd come across as a junior, having been impressed by their positive qualities.

What is an alcoholic?

Someone with distinct alcohol dependence. The terminology that I've just used, and indeed the whole terminology on dependence and addiction is in a constant process of revision. Alcoholic remains a useful term instead of severe problemdrinker, or alcohol-dependent patient. Similarly with alcoholism, as a traditional and short alternative for dependence on alcohol. I'm glad to note how ICD-10 specifies that alcohol dependence refers to alcoholism.

How did your interest in alcohol, and drugs, develop?

Having newly opened an alcoholic unit in 1961, it was then said that I might treat drug addiction too. Addiction was the fashionable term at that period. That went out of favour and is now regaining respectability.

At that time persons addicted to drugs were people who were therapeutically dependent: to opiates, but more particularly to amphetamines and barbiturates which were obtained on prescription. Street heroin was unknown in this country; that was something which was only found in the United States.

So the socio-demographic characteristics of the patients would be different from what they are now.

Exactly, and they resembled those of the alcoholics. They fitted in quite well together.

How did your interest and the service develop?

When we opened the unit at Moston Hospital in Chester it was the second of its kind in the country after Max Glatt's in London. We accepted patients from a very wide area, from Anglesey, right through Manchester, and up to the Lake District.

Like other units that concentrated on alcoholism treatment, we initially dealt only with inpatients but quite quickly moved, as did comparable centres, to treating out-patients instead of admitting them, or using the period of in-patient treatment as a preamble to subsequent out-patient counselling. Alcohol treatment units have been criticised unfairly, and still are to this day, as concentrating on in-patient treatment. That, as the exclusive, or even as the main focus of therapy was discarded over 20 years ago.

What has been the value of alcohol treatment units?

The value comes in setting up a specialist treatment service, largely for out-patients, although with necessary in-patient beds, and in some services day hospital provision as well. The units also stimulate other agencies to take an interest in alcoholism. For example, the voluntary agencies for alcohol counselling have often been initiated by psychiatrists specialising in that area. Additionally, the specialist units serve as centres of teaching and research.

How big was the addiction unit?

It was called an addiction unit because it was for drug addicts as well. The in-patient side possessed 28 beds as a nucleus for a constantly increasing network of specialised community services until I retired at the end of 1991

What changes did you see in services from the '60s onwards?

There has been a proliferation of specialised centres. There are now about 30 . The treatment 
unit, as I have indicated, moved away from concentrating on in-patient treatment which is now seen as just one facet of a package of specialised provisions. Furthermore, the in-patient side of treatment became shorter. Then controlled drinking became a more acceptable goal for those who are not clearly dependent. Those who are not dependent don't usually need admission to hospital of course.

How did you see the use of the unit for alcoholics in the years just before your retirement?

Trying not to admit them. Having said that, we admitted at least half of those we saw, although usually after a period of out-patient treatment. There were two common reasons for admission. Either the patients kept relapsing or they simply couldn't detoxify outside hospital despite a short course of a benzodiazepine. We built up the day centre side and the community psychiatric nursing side.

I should say that on the question of admitting alcoholics we are talking about people with distinct alcohol dependence. They are the patients who come the way of psychiatrists, especially psychiatrists who specialise in addiction. Most people who misuse alcohol are only minimally dependent or are not dependent at all; most of them don't get as far as seeing a psychiatrist, and rightly so. They are the subjects for whom GPs and voluntary agencies largely take over the counselling side.

Are you happy with the distinction between alcohol dependence syndrome and alcoholrelated problems?

Alcohol-related problem is a wishy-washy term that should be replaced with problem caused by alcohol'. Not that alcohol need be regarded as the only causative feature; there are obviously other factors, yet if you remove alcohol the problem very often subsides, perhaps not completely, but substantially. Alcohol-related is a misleadingly weak expression.

I'm interested in the treatment of withdrawal symptoms over the last 30 years.

With benzodiazepines, chlordiazepoxide particularly, although also with diazepam, we have made major advances. The death rate from delirium tremens is virtually non-existent in this country. That was not the case when we relied on barbiturates, so there has been a remarkable decrease during this century. The death rate from delirium tremens approached $30 \%$ as recorded in the textbooks at the beginning of the century. It is unclear why that is; I don't think it's entirely because of modern drugs, including benzodiazepines; it's perhaps because patients are more ready to come for treatment and we're more ready to treat them at earlier stages.

What about Korsakoff's syndrome and Wernicke's encephalopathy?

Most of the work on them in recent years has been conducted by neurologists and neuropathologists rather than psychiatrists. That statement rather gives the game away. The conditions are uncommon, particularly Korsakoff's psychosis, though it is likely that we do miss cases of Wernicke's encephalopathy, perhaps misdiagnosing the condition as a withdrawal state.

As regards severe cognitive deficits from alcoholism, they are rare in this country although not always elsewhere. In Australia and New Zealand Korsakoff states have been very common, albeit with decreasing incidence over the last few years. On the other hand, minor degrees of brain damage, not evident at psychiatric interview, are found by psychometry or neuroimaging in about $50 \%$ of alcoholic patients. The deficits improve with prolonged abstinence.

Can you explain the origin and progress of the idea of controlled drinking?

There were early papers on this but it was rediscovered by D.L. Davies from the Maudsley, and his social worker colleague, Myers. They described a small number of patients who appeared to have alcoholism and seemed to change to a moderate use of alcohol. Later those patients were followed up by Griffith Edwards, who concluded that one hadn't been alcohol-dependent at all, that most were no longer controlled drinkers and, in fact, that not all were controlled drinkers at the time that the original study had concluded they were drinking in a moderate way. This doesn't alter the fact that people with alcohol problems, even severe ones, can sometimes become controlled drinkers. But the difficulty with those who are alcohol-dependent is you can't predict who will be capable of controlled drinking.

\section{Have you seen successful controlled drinking?}

I have encountered patients who after a period successfully decided not to follow my advice of remaining abstinent. I have met them, not necessarily because they needed to see me but for other reasons and they have indicated that they've been having the occasional drink. I didn't see any reason why they should be less than honest.

\section{Would you say controlled drinking works?}

Not as a sensible option for those who are distinctly dependent. Some patients, even with severe dependence, can go on to life-long 
controlled drinking but they are in the minority, and as we can't forecast who will fall in that minority, it is prudent to advise abstinence.

How has the drug addiction field changed over the last 30 years?

That has shown a more remarkable change because of the introduction of illicit drug misuse, which was really non-existent in the early 1960 s. Illicit drug misuse first took-off in the UK in the mid 1960 s with a mixture of drugs. The one that got most prominence was heroin but there were also amphetamines taken illicitly and LSD. It was because of the spread of street use of LSD and of intravenous methamphetamine that these two preparations were withdrawn by the pharmaceutical companies and became unavailable for psychotherapy.

How did the drug culture develop in Cheshire?

It was rather slow getting off the ground in Chester compared with Liverpool and Birkenhead. The situation was largely as it is now, a question of use among the less affluent strata of society. In the United States, LSD was taken through the promulgation of Timothy Leary as a sort of intellectually superior exercise but in Merseyside and through most of the UK the drug did not have that aura.

Were you dealing with cases of LSD use?

Only a few who felt it was their main problem, but there were many others who took LSD, amphetamines, heroin, whatever was around, or in fashion at that time.

\section{What was your main treatment approach?}

It was abstinence oriented. The illicit drug scene had been established in Liverpool for a couple of years when the police in Liverpool informed me that they knew of only a dozen heroin takers. At that time the heroin epidemic, which was the term in use, was confined to London. Addiction to heroin existed outside the metropolis but merely in small numbers. It was only in the late 1970 s and particularly in the 1980s that the phenomenon extended to provincial cities in a major way.

What was the rational basis for abstinence?

On the grounds that the patients were producing severe problems for themselves and sometimes for others, but particularly for themselves, by the use of drugs and that they weren't able to use the drugs in moderation. Obviously we didn't see for treatment the people who were 'chipping' heroin (taking it perhaps three or four times a week, not three or four times a day).
Have you been a career-long proponent of abstinence?

When the drug treatment clinics were set up in the late 1960 s they were mostly in the London area where there were several hundred people dependent on heroin prescriptions. Some were using curious medical sources which were stopped by the Dangerous Drugs Act of 1967. When psychiatrists took over they rather quickly moved patients from heroin prescriptions to methadone prescriptions and stopped the cocaine prescriptions patients were also receiving. In the 1970s there was a gradual disillusion in the London clinics with methadone treatment. It just wasn't helping to keep the patients off heroin. But this was reversed in the 1980 s by the introduction of HIV infection and with the need to stop its spread between and from intravenous drug injectors. So methadone treatment as a period of substitution therapy, not necessarily prolonged, came back into vogue.

I've seen these fashions in treatment for drug misuse, and I just wonder what will happen next. I am sceptical about the value of methadone treatment for many of its recipients. Not for all; there is no doubt that there are some addicts who cease or substantially reduce their injecting practices but many do not attain that goal for long.

Did you remain in general psychiatry all the while?

I remained a general psychiatrist until I retired and maintain an interest now. As the years went by, substance misuse gradually took over, so that towards the end, three quarters of my time was spent with alcohol and drug misusers. I made sure to retain a workload in general psychiatry, not simply because of contractual obligations but also because of the attractions of the patients and of their illnesses.

Did you have any special interest in general psychiatry or did you take a broad sector of responstbility?

Broad sector, not a geographical sector. As mentioned. I was the first consultant for a day hospital. Later, in the 1970s, I became the initial consultant of a rehabilitation unit for long-stay patients. That was quite enjoyable; many of the patients did quite well, not thanks to me but due to the professionalism of the nurses.

Can we turn to changes you have seen in general psychiatry since your early days as a consultant?

One is the liberalness with which we used to admit people with neurosis, on the grounds that a period of in-patient psychiatric treatment. perhaps with some psychotherapy, might help them. Nowadays we don't do this. The swing 
away from admissions of neurotic patients began before the run-down in admission beds, as a change in psychiatric rather than administrative practice.

Would you draw attention to changes in diagnostic fashion?

Patients are quick to pick up and mimic the syndromes that interest doctors. In my early years in psychiatry neurasthenia was not uncommon. The advent of antidepressants meant that doctors began doing something useful (or at least gave the appearance of doing something useful) with prescriptions for depression-so neurasthenia completely disappeared. I am relieved to see it's now coming back under other names. It should be noted that at the present time doctors in Western societies will tend to ask if a patient is depressed rather than whether the patient feels tired.

The other change is in respect of anxiety. Anxiety states were quite common in the 1950 s and early 1960s. They too almost disappeared from psychiatric practice with the advent of antidepressants, although for a shorter period than symptoms of fatigue. The patients were influenced by the doctors. . In my early years it was often a mental 'toss-up' on the part of the psychiatrist whether anxiety state or reactive depression was employed as the diagnostic label.

A further major difference is the number of people who were in mental hospitals with epilepsy.

This primary diagnosis led to their alienation and sequestration in long-stay wards. The psychiatric hospital at Chester had a special ward for epileptics as a single storey building. Patients were apparently allowed to have fits at home on staircases but not in the hospital.

What other changes in therapeutic fashion could you comment on?

The two major declines in treatment popularity are in leucotomy, and the selection of patients for ECT.

Unilateral ECT was invented by Isaac Frost who was a senior consultant at Chester.

He was concerned about the adverse consequences of ECT and rather doubted whether the treatment was particularly effective. Like Aubrey Lewis he thought the less electricity he gave to the patient the better. In a large mental hospital in those days 50 or 60 patients would be given the treatment twice a week, many of whom were long-stay patients with chronic illnesses, not just people with an episode of affective disorder.

ECT was administered in the hope of benefiting patients but it was over-used on people with chronic illnesses. Of course, at that time in the mid-1950s the tranquillisers were only just emerging so psychiatrists really didn't have much else in the line of other treatments apart from leucotomy and for the milder disorders drug-assisted psychotherapy. Long-term drug treatment to maintain health in schizophrenia and affective disorder was unknown.

\section{Can we move on now to your College activities?}

I was associated with its predecessor the Royal Medico-Psychological Association, not at national level but at divisional level. Later I was involved with the College, again at divisional level.

My more intense involvement developed because of substance misuse. The Dependence/ Addiction Group was founded in the early 1980s. That was a horrendous title. Dr Brian Hore was its first chairman; he was succeeded by $\mathrm{Dr}$ Thomas Bewley who retired on his election to the presidency and I succeeded him. Subsequently the Group was elevated to the much higher status of a Section. So I became the first chairman of the Substance Misuse Section. I am happy to say that we found a better title than 'Dependence/Addiction'.

I was chairman for four years and before that I had been for about a year and a half chairman of the Dependence/Addiction Group.

What was the significance of your chairmanship of that Section?

Elevation to Section status meant that the College more regularly included substance misuse in its considerations. For example, when matters came before the Public Policy Committee, perhaps referred from the Department of Health or from the Home Office, it then became routine to look at the implications of substance misuse and at their bearings on the College's response.

The Section published in Psychiatric Bulletin two reports, approved by the College, that deal respectively with manpower and training needs and with a model of drug dependence services at district level. One of our main concerns has been to raise the quality of training for senior registrars in substance misuse and the number of senior registrars willing to go into the subspecialty and thereby to increase the number of consultants in substance misuse.

The College and health authorities have made some progress in improving consultant input. But we haven't progressed very far with the numbers of senior registrars.

It is not because of the unattractiveness of the training or of the work. Substance misuse is not the only psychiatric disorder in which relapses 
can occur and many patients with alcohol or drug problems actually do quite well. I think it's partly because there hasn't been sufficient expansion as yet of consultant posts. Senior registrars in training look at the job advertisements noting in which types of work the vacancies lie and recognising that there are more in some other specialities and sub-specialities, particularly in psychogeriatrics, than there are in substance misuse. It hasn't helped here, particularly on the drug misuse side, that certain health authorities have either handed over the treatment services largely, if not entirely, to doctors who are general psychiatrists who were already in post and who have no specific training or experience in drug misuse, or given the services over to doctors who are not even psychiatrists. Both practices limit the number of new vacancies in the sub-specialty and therefore reduce its attractiveness for senior registrars.

Or have handed it over to non-medical voluntary sources.

You still need doctors for drug misuse. The nonmedical voluntary agencies, while one need not necessarily agree with everything every agency does, should on the whole be encouraged. Indeed, I have been chairman of the Merseyside Drugs Council.

I want to ask about your involvement in editing Alcohol and Alcoholism.

Under its previous title British Journal of Alcoholism the journal had been published for a dozen years. It served a two-fold role as an academic journal and as a journal of educational interest to general practitioners. The mixture was uneasy. However, I contributed from time to time, mostly articles of a historical nature about well-known people who had quite severe alcohol problems. For example, Beethoven, for which I was taken to task by Alan Coren in Punch with an article headed 'Careful Mr Beethoven, that was your fifth!'. I wrote on Dr Johnson (whose mountain is behind the mental hospital in Denbigh) and on Prince Charles Edward Stuart. I had also written research articles so when the journal changed its title and became purely academic I was invited to become its assistant editor. Later there was promotion as joint deputy editor.

There is a large group of addiction journals now but Alcohol and Alcoholism is among the leaders. The journal progressed from quarterly to two-monthly issues across the short interval of six years. Many of its papers, because of the interests of its successive senior editors, deal with the organic side of alcohol problems. It's my role to keep up the psychiatric, psychological and sociological aspects.

Any other activities in the writing or editing field?

I wrote a book which went into two editions that were both translated: A Guide to Alcohol and Drug Dependence. It was intended as a text for the professional reader who encounters people with alcohol or drug problems, not only psychiatrists but other doctors, psychologists and social workers. That took two years out of my life but it was worth it.

Then I am involved as a section editor of Current Opinion in Psychiatry. I find that quite rewarding. For the first three years I was sole section editor. Then the policy was changed to involve joint section editors from abroad, particularly from the United States. So I have recently collaborated with Bob Schuster from the National Institute of Drug Abuse in Baltimore. Maryland. We have taken alternate years in the leading role of inviting experts to review fresh researches. I am just putting to bed now an issue of the 'Substance Misuse' part of Current Opinion in Psychiatry.

What other jobs have you continued since your retirement in 1991 ?

Since I retired I undertook a consultant advisory post on substance misuse in a Middle Eastern country. My advice was not to concentrate on the large in-patient treatment units to which almost every patient was routinely admitted. The staff in the in-patient units should admit fewer patients but develop out-patient facilities and additionally train other professionals within and without medicine to conduct counselling.

A function nearer home is that you are Chairman of the Merseyside, Lancashire and Cheshire Council on Alcoholism.

This was the forerunner of the voluntary alcohol agencies. The council has organised eight international conferences on alcohol misuse. Both its counselling services and its hostel have emerged unscathed from the 1993 tribulations of national changes in funding.

You are also involved with the Medical Councll on Alcoholism.

This sees its main role as development of medical education at undergraduate and postgraduate levels. In addition to publishing Alcohol and Alcoholism the organisation provides excellent instructional booklets for medical students and nurses; those for medical undergraduates are distributed free of charge. The body is developing 
fresh interests under its new Chairman, Bruce Ritson, and recently appointed Director Peter Abraham; they are both psychiatrists.

At the present time there is emphasis on the dual diagnosis of patients with substance misuse and with another psychiatric disorder.

This is partly an artifact of the coaxial presentation of DSM-III-R and can lead to difficulties in that patients are not recognised or treated as primarily substance misusers. For example, the concept of co-morbidity in an alcoholic patient who is secondarlly depressed or anxious can divert therapeutic attention from the cause of disordered affect, namely the drinking.

We see an increasing number of people with schizophrenia in the community with drinking problems and in the United States with drug problems.

Formerly you just didn't see schizophrenics who took heavily to alcohol; they were in hospital, or if in the community they were too shy or withdrawn to visit the local hostelry. But nowadays schizophrenics are not retained in hospital and there is an increased avallability of home forms of beverage, so some of these solitary people sit sadly drinking in their isolated living quarters. Then they tend to fall between two treatment services. Substance misuse professionals don't wish to treat them because of the psychosis, and the general psychiatric services find the patients difficult because of problems induced by alcohol.

Identification of a key worker, such as a community nurse from general psychiatry or from substance misuse would assist.
You have been involved with the General Medical Council and its helpful arrangements for doctors who are ill.

Usually the illness is psychiatric, generally taking the form of alcohol or drug misuse. The GMC adopts two alternatives for dealing with doctors who come to its notice and who require more than simply a warning letter as a 'shot across the bows'. The issues are treated either as disciplinary or as health matters. The latter course is now generally chosen. The doctor consents to treatment and supervision by a consultant psychiatrist who reports at intervals to the GMC; the system has been successful in restoring doctors with alcohol or drug problems back to work.

\section{How does the GMC system work?}

It relies on reports from the supervising consultant which continue over a number of years for each doctor. About a third are eventually taken off supervision. That is quite a remarkable difference from the former more disciplinary procedures. The system depends within the GMC on the Preliminary Screener and his Deputy. When the scheme was established in the early 1980s the original Preliminary Screener was Philip Connell, whose Deputy was Neil Kessel; now Neil is the Screener and his Deputy is Thomas Bewley. The GMC keeps to the forefront the need to safeguard the public but also considers in an impressive manner the worth of experienced and rehabilitated doctors.

In fact in recent years one of the most enjoyable parts of my duties was that of a consultant engaged in the treatment and supervision of doctors. 